\title{
Por uma abordagem interseccional das desigualdades: rupturas com visões hierarquizadas
}

\author{
Lucas Hertzog' \\ Luciana Garcia de Mello²
}

Resumo: Este artigo tem por objetivo propor uma reflexão sobre a possibilidade de abordar as diferentes formas de desigualdades e de processos de exclusão sem hierarquizá-los. Para tanto, realiza uma crítica do pensamento social brasileiro, notadamente o de Jessé Souza, apresentando como alternativa a abordagem teórico metodológica da interseccionalidade. Assim, ao invés de se pensar as desigualdades por meio dos mecanismos que realmente importariam para demarcar a posição social dos indivíduos, aposta-se em alternativas teóricas que permitam analisar universos de pesquisa em que se apresentam questões de raça, classe, gênero, orientação sexual, identidade nacional, entre outras, de modo interseccional. Dessa maneira, focalizam-se esses universos de modo relacional e contextual, levando-se em conta os efeitos interativos desses marcadores sociais.

Palavras-chave: Desigualdade social. Interseccionalidade. Classe. Raça. Gênero.

1 Centre for Social Science Research, University of Cape Town (CSSR, UCT) - Cidade do Cabo - África do Sul-ramos.lh@gmail.com

2 Programa de Pós-Graduação em Sociologia da Universidade federal do Rio Grande do Sul (PPGS UFRGS) - Porto Alegre - Brasil - lusociais@yahoo.com.br 


\section{An intersectional approach to inequalities: ruptures with hierarchical views}

Abstract: This article proposes a reflection on the possibility of addressing the different forms of inequalities and processes of exclusion without hierarchizing them. To this end, it conducts a critique of Brazilian social thinking, notably that of Jessé Souza, presenting as an alternative the methodological theoretical approach of intersectionality. Thus, instead of thinking about inequalities based on the mechanisms that would matter to demarcate the social position of individuals, we rely on theoretical alternatives that allow us to analyze research universes that present issues of race, class, gender, sexual orientation, national identity, among others, intersectionally. Thus, these universes are focused relationally and contextually, taking into account the interactive effects of these social markers.

Keywords: Social inequality. Intersectionality. Class. Race. Gender.

\section{Introduç̃̃o}

Pensar as desigualdades sociais em termos hierárquicos, por meio dos mecanismos que realmente importariam nos processos de exclusão, tem sido recurso de uma série de acadêmicos alinhados ao campo epistemológico da sociologia crítica. A classe, nesse contexto, como forma de pertencimento que atravessaria todos os planos ou esferas da existência, teria um papel preponderante, sendo um fator causal com peso decisivo para a exclusão social. Partindo deste ponto, sugerimos neste artigo uma discussão sobre os desafios de (des) hierarquizar categoriais propostas a pensar universos de pesquisa, como classe, raça, gênero, orientação sexual, identidade nacional, entre outras formas de pertencimento. A ideia principal é analisar esses universos de modo relacional para focalizar seus efeitos interativos. Partimos de uma análise do pensamento social brasileiro, e de modo mais específico dos desenvolvimentos da teoria de Jessé Souza nos quais o autor propõe a hipótese que o preconceito no Brasil seria condicionado pelo pertencimento de classe, caracterizando os outros processos de discriminação com epifenômenos deste elemento chave. Articulamos tal suspeita com as teorias da interseccionalidade, cujas ramificações se estendem a diversos campos epistemológicos como o realismo crítico, o pós-modernismo e o pós-estruturalismo.

Nosso objetivo central é destacar a importância da abordagem interseccional para pesquisas sociológicas que busquem explorar a heterogeneidade dos 
universos de pesquisa sem o aplainamento das singularidades dos atores em contextos de vulnerabilidades sociais. Tal perspectiva permite refletir como as diferenças - que vão se tornando desigualdades - são socialmente construídas, sem que se adote, sempre e em todas as vezes, como ponto de partida um único elemento.

\section{A hierarquia da desigualdade em Jessé Souza}

Em artigo intitulado Raça ou classe? Sobre a desigualdade brasileira, o sociólogo Jessé Souza (2005) pretende demonstrar ao seu leitor uma hierarquia das causas da desigualdade, sendo a desigualdade brasileira marcada e determinada pela classe social, variável que sobredeterminaria as demais. As outras formas de exclusão, como no argumento em questão o preconceito racial, seriam residuais, ou como prefere o autor, relativos e dependentes da variável mais importante, o preconceito de classe, levando-o cunhar a expressão "racismo de classe".

A exclusão social dos negros na periferia do capitalismo, como o caso brasileiro, seria uma variável dependente da falta de incorporação por um terço da população brasileira (Souza, 2009) de uma economia emocional peculiar dos desdobramentos de uma cultura europeia - uma noção historicamente construída e culturalmente contingente de personalidade e condução da vida -, que se constitui naquele continente "entre os séculos XVII e XVIII, que passa a ser o núcleo duro da hierarquia valorativa incrustada de forma opaca e intransparente no funcionamento destas instituições fundamentais [mercado e Estado]" (Souza, 2005: 57). O argumento vai na linha de reelaboração das teorizações de Pierre Bourdieu (2007) sobre o habitus de classe ao contexto brasileiro: haveria no contexto periférico a massificação do que Souza chama de um "habitus precário", que se refere a um modo peculiar de condução da vida que caracteriza as formas socioculturais incorporadas, em larga medida, por uma classe que o autor conceituará posteriormente como "ralé estrutural"3. Resumidamente poderíamos perceber no interior do argumento um movimento duplo, de desracialização do habitus precário e de complexificação do conceito de classe social, o que arriscaríamos denominar a construção de um conceito forte de classe.

3 Esse conceito foi cunhado por Florestan Fernandes (1978) para se referir à população negra no pós-abolição. Jesse Souza faz uma releitura de Fernandes e passa a afirmar que essa condição não diz respeito somente aos negros, mas aos pobres de um modo geral. É nesse sentido que Souza considera que ralé é classe e não se refere ao pertencimento racial. Não haveria, portanto, diferenças significativas entre a situação de anomia de negros e brancos pobres. 
O argumento de Souza é construído pela tentativa de demolição de dois essencialismos: culturalista e econômico. Na perspectiva do autor, haveria um grande número de trabalhos na sociologia brasileira, como por exemplo a obra de Carlos Hasenbalg, que dariam ênfase em demonstrar a sobrerrepresentação dos negros nos índices sociais negativos (2005; Hasenbalg; Silva, 1988). Segundo o sociólogo potiguar, tais estudos apenas apresentariam correlações entre raça e exclusão social, mas não explicariam como se efetivariam tais correlações e não comprovariam o papel relativo da variável racial na produção da desigualdade. A saída para tal confusão seria a tomada de um quadro de referência teórico amplo, "inclusivo e totalizador" (Souza, 2005: 45). O movimento duplo, de combate ao economicismo, estaria na proposta de uma teoria de classes que abarcasse elementos não econômicos na edificação do que seria uma classe social; assim poder-se-ia perceber que classe não é apenas condicionada por certo patamar de renda e que os mecanismos da exclusão social podem ser elucidados quando compreendermos que são os efeitos de pertencimento de classe na variável racial, e não o contrário, que explicariam preconceitos de toda sorte no contexto brasileiro. Assim, trilha o caminho do universalismo teórico dedicado a abarcar a totalidade do fenômeno da exclusão social.

O autor busca na teoria de Pierre Bourdieu os elementos que este traz de Karl Marx e Max Weber para sua elaboração de uma teoria da estratificação, que combina aspectos econômicos e socioculturais, passando a vincular a situação de classe a formas de condução da vida específicas. A determinação da classe sobre o comportamento humano - ou o fato de que a classe atravessaria todos os planos da existência - constituiria a dimensão marxista do conceito, enquanto em Weber é buscada a bidimensionalidade da estratificação, mesmo que por meio de uma substituição do "aspecto da honra pelo tema do prestígio associado ao conhecimento, ou "capital cultural", como ele [Bourdieu] prefere". (Ibid.: 46).

A forma de condução da vida específica que Souza busca demonstrar como elemento distintivo da relação dos sujeitos com o mundo social é uma noção que se desenvolve no continente Europeu pela influência do protestantismo ascético como amálgama entre condições institucionais de desenvolvimento do capitalismo e condições pessoais de engajamento em formas modernas de relacionamento interpessoal (fundamentados sobretudo pelo caráter impessoal das relações).

Partindo de uma leitura weberiana, Souza depreende seu argumento de que esta forma particular e culturalmente contingente de personalidade passa a separar e unir pessoas e grupos sociais em superiores e inferiores por vínculos de 
solidariedade e preconceito. Neste ponto percebemos o núcleo que erige a ideia de que maneiras de ser e performar no mundo social, ou o modo distintivo peculiar e que chama a atenção do observador, separariam e uniriam indivíduos por vínculos afetivos, independente da expressão fenotípica que apresentem.

Encontramos adiante no artigo seu argumento central sobre o que constituiriam as classes sociais, diferenciadas não apenas pelo poder de consumo material, mas por elementos não econômicos como a noção de disciplina e controle do corpo e de suas emoções e necessidades, que acabam por "diferenciar imperceptivelmente classes sociais, gênero, etnias etc." (Ibid.: 49-50). Observando o desdobramento do conceito de habitus de Pierre Bourdieu e de anomia, tal como empregado por Florestan Fernandes (1978), Souza propõe o conceito de habitus precário.

$\mathrm{O}$ argumento central é que mercado e Estado possuem uma hierarquia peculiar e subjacente às suas práticas institucionais e que determinam as relações interpessoais, na medida em que edificam e legitimam distinções sociais que vão para além dos critérios de eficácia formal. Haveria aqui a materialização de concepções de mundo, que passam a separar indivíduos em grupos diferenciados, seja no realce de suas qualidades individuais ou na sobredeterminação de suas carências emocionais.

Uma cultura e concepção de mundo contingente estariam associadas à lógica institucional do capitalismo moderno e explicariam de que modo a cultura e os valores influenciariam o comportamento humano. Seguindo o argumento de Weber (2004), o alicerce da hierarquia valorativa incrustada no funcionamento das fundamentais instituições modernas (mercado e Estado) teria sido edificada por estímulos oriundos das orientações do protestantismo ascético, "que constrói essa noção contingente e única de agência humana" e que "passa a ter agora como suporte secular à lógica impessoal de mercado e Estado que reproduz, através de estímulos empíricos como dinheiro e coerção legal, o mesmo tipo de indivíduo que antes a fé produzia” (Souza, 2005: 57). Depreende, deste ponto, sua concepção de que o preconceito se ampararia, primordialmente, nestes critérios, uma concepção dominante do valor diferencial entre os seres humanos e grupos sociais que não possuiria relação com o preconceito naturalista que vincularia a "europeidade a um fenótipo ou tipo físico do indivíduo de olhos azuis e cabelos loiros" (Ibid.).

Instigante, neste contexto, é refletir que esta concepção dominante do valor diferencial entre seres humanos e grupos sociais tenha sido justificada e legitimada, por diversas vezes, pela superioridade fenotípica do europeu sobre os colonizados, com especial agravo quando estes eram africanos e indígenas. 
Mesmo no interior do continente o fenótipo sempre foi objeto de disputa, favorecendo os sujeitos de pele mais branca e com aspectos caucasianos. Esse processo, de emergência do europeu enquanto símbolo máximo do que podemos atingir enquanto sociedades igualitárias, ou de exemplar fidedigno de uma cultura emocional realçada como digna de emancipação do ideal humano foi, ainda que amparada num ethos e numa forma de condução da vida, fundamentada na exploração colonial fenotipicamente autorizada. Isto posto, torna-se laborioso e até mesmo contraditório recusar que o fenótipo foi e ainda é aspecto determinante nos processos de exclusão que operam por meio de mecanismos de opressão institucionalizados nas práticas dos atores sociais e nas principais instituições modernas.

Souza argumenta que o preconceito que opera em terras brasileiras é um preconceito "que se refere a certo tipo de personalidade, ou seja, em relação a um habitus específico, julgada como improdutiva e disruptiva para a sociedade como um todo" (Ibid.:59). Que a alegação seja verdadeira não invalida que tanto agentes institucionais como sujeitos comuns façam associações deste tipo de personalidade com a cor da pele, textura do cabelo e outros traços fenotípicos, produzindo e reproduzindo nas interações cotidianas a hostilidade racial.

Mesmo defendendo tal argumento de que a exclusão se efetiva diante da segregação entre pertencedores e carentes de uma certa economia emocional, Souza reconhece a existência do preconceito racial, assim como o preconceito de gênero. Sua explicação se dá por meio da uma suposta associação inconsciente e pré-reflexiva:

Do mesmo modo [que o preconceito de gênero], a "raça branca" é associada à europeidade e sua herança cultural de controle dos instintos e necessidades corporais em favor do autocontrole e disciplina. A "raça negra" é considerada inferior pela associação ao "primitivismo" africano que é percebido como repositário de valores ambíguos como força muscular e sensualidade (Ibid.: 59).

A despeito de que a associação tenha produzido e produza efeitos nas relações entre etnias e gêneros, não fica claro ao seu leitor se está se referindo ao senso comum em relação aos europeus [brancos] e africanos [negros], ou é uma associação sugerida pelo autor como leitura das causas do racismo propriamente. Quando raça negra seria considerada inferior e raça branca associada a europeidade? Quando tal associação seria suspensa? Aqui parece haver uma tentativa de levar o argumento da dissociação do corpo daquilo que nele se 
inscreve, como se negros integrados e que incorporaram os traços da europeidade abrandassem o racismo, hipótese de difícil sustentação.

Diferentemente de Souza, Anibal Quijano (2000) situa a construção social da raça no contexto das relações que passam a existir com a colonização e o processo de formação do mercado globalizado. Quijano chama atenção para o fato de que desde esse período emergiu uma relação que não existia em momentos anteriores da história, já que identidades geográficas passam a dar lugar a identidades racializadas. Desse modo, o termo europeu, por exemplo, que até então indicava procedência geográfica ou país de origem, ganha uma conotação racial. A associação pré-reflexiva que Souza destaca, pode ser colocada, então, como "instrumentos de classificação social básica na população", nas quais se configuram relações de dominação, em que as identidades raciais e a raça são "associadas às hierarquias, lugares e papeis sociais correspondentes [...] e, consequentemente, ao padrão de dominação que se impunha” (Ibid.: 228-9)

Se tal associação circunscreve de fato as relações entre sujeitos e instituições, entre brancos e negros que nelas se inscrevem, nos deparamos com a contradição do argumento da justaposição que se faz entre classe e raça. Existindo o racismo, como afirmar como argumento irrefutável a hierarquia entre processos de exclusão? Se, especificamente no Brasil, ocorre um processo de hierarquização baseado na raça e que não foi de maneira alguma sobreposto por políticas da diferença que acompanhem as necessidades materiais e subjetivas de toda a população racializada, como definir em absoluto e a priori as premissas e condições de perpetuação de uns à margem dos benefícios da nossa "modernização seletiva"?

Em relação ao substrato que torna possível a consecução da exclusão via preconceito racial, torna-se fundamental que questionemos o quanto representam tais formações arquetípicas e sua relação intrínseca com o desenvolvimento do humanismo ocidental no centro da Europa como melhor resposta - ou mais adequada até então - à resolução das questões sociais dos subdesenvolvidos, partindo de Europa como centro e modelo a ser seguido. Segundo Aníbal Quijano, o novo padrão de poder mundial eurocentrado tem como um dos eixos fundamentais a:

[...] classificação social da população mundial de acordo com a ideia de raça, uma construção mental que expressa a experiência básica da dominação colonial e que desde então [da culminação da globalização como processos que começa na constituição da América e do capitalismo colonial/moderno] permeia as dimensões mais importantes do poder mundial, incluindo sua racionalidade específica, o eurocentrismo" (Quijano, 2000: 227). 
O humanismo como resposta à escuridão, figurando a Europa (bem como os Estados Unidos) como matriz dos projetos nacionais de desenvolvimento moral, coletivo, econômico e político de maneira geral, depara-se com contradições incontornáveis no período pós-colonial em que as sementes europeias espalhadas mundo afora passam a ser colhidas em seus territórios, nas formas de ódio, preconceito e segregação dos corpos racializados e da racionalização dos territórios. Ainda, uma releitura histórica do desenvolvimento político, estético e filosófico das sociedades africanas, seja nos dias atuais ou na sua reconstrução histórica, embaralham essa pretensa noção de primitivismo, na qual se imporia uma relação desenvolvimentista associada aos ganhos e acúmulos materiais possíveis por meio do desenvolvimento da indústria capitalista que colocam África - e acrescentaríamos a América Latina - em relação de subdesenvolvimento (Hountondji, 2008).

Souza sugere que tal associação que liga brancos aos europeus [herança positiva] e negros aos africanos [herança negativa], não seria a causa principal da marginalização de negros ou brancos. A hierarquia da ordem competitiva marginalizaria e desclassificaria tanto negros quanto brancos sem qualificação adequada, sem qualquer ligação aos resíduos de épocas passadas. $\mathrm{O}$ autor reconhece que tal associação exista, embora ela não seria explicativa para os fenômenos da exclusão social como queria Florestan Fernandes. Os depoimentos trazidos pelo clássico estudo do sociólogo paulista traziam aspectos conspícuos da hierarquia valorativa do racionalismo ocidental moderno: ausência de ordem, disciplina, previsibilidade, raciocínio prospectivo etc. Inexistiriam "mundo dos negros" e "mundos dos brancos", dado que ambos não seriam realidade essenciais e independentes, já que sua hierarquia valorativa é única e subordinaria tanto brancos como negros ${ }^{4}$.

Questionamos, partindo deste ponto, como é possível pensar que uma hierarquia valorativa em um contexto racista subordinaria brancos e negros de maneira igual? Esta hipótese, de que a hierarquia valorativa seria neutra em relação à cor da pele - ou relegada a elementos patológicos e virulentos - é de difícil comprovação sociológica. Um ponto de partida sociológico mais instigante é pensarmos que resíduos não foram, eles são e estão inscritos na carne dos corpos que habitam o mundo hoje. Nesse sentido, colonialismo europeu, escravidão, e todos os acontecimentos históricos que sedimentam o hoje não são continuação inercial do passado como sugere Souza. O passado não é apenas

4 É importante sublinhar que Florestan Fernandes (1972) argumenta que a hierarquia valorativa é definida pelos brancos. É, portanto, nesse sentido, que o autor afirma que os negros vivem no mundo dos brancos. 
redefinição moderna como também sugere o autor, mas afirmação cotidiana de acontecimentos que são e não simplesmente foram.

Segundo Souza, negros e mulatos sempre puderam se integrar na comunidade nacional, já que o esforço modernizador faria com a nação por meio de seus desenvolvedores estivesse mais interessada numa economia emocional necessária à produção, sendo irrelevante a raça do sujeito desde que produtivo e útil. Aqui, haveria uma estratégia de "embranquecimento", cujo correspondente no caso americano é a "passagem" (passing) "quando o indivíduo de cor branca de ascendência negra nega sistematicamente sua origem" (Souza, 2006:87). Os negros e mulatos, no caso brasileiro, poderiam se integrar e seriam aceitos desde que contribuidores "efetivos ou potenciais do esforço modernizador, o grande elemento galvanizador da solidariedade interna brasileira desde a independência nacional" (Souza, 2005: 63). Poderiam, então, desfrutar de reconhecimento social, o que para Souza traduz os processos de embranquecimento possíveis mediante a integração na esfera produtiva.

Como argumenta Marcia Lima (2012) em relação a essa ideia de Souza, "se o dinheiro5 'embranquece' e não apenas enriquece é sinal de que há uma relação entre esses fenômenos e que o atributo racial é sim um componente analítico importante para compreender a estrutura de classes" (p. 248). Lima sugere ainda que, mesmo que achados de estudos anteriores permitam assumir que contextos socioeconômicos são cruciais para o entendimento das desigualdades raciais, "o potencial analítico da variável raça deve ser medido segundo o contexto investigado". É precisamente neste ponto, de busca pelo contexto da ação, que gostaríamos de sugerir uma releitura da hierarquia das causas da desigualdade defendidas por Souza. As desigualdades correspondem a processos sócio históricos multifacetados e nem sempre é possível precisar qual a sua dimensão mais importante. Nesse sentido, os estudos sobre esse tema não podem prescindir de uma análise contextual que permita compreender de que modo esses processos são construídos.

Se atentarmos a outros textos do autor, veremos que na construção de seu argumento da modernização seletiva (Souza, 2000), a questão racial é fundamental. Em A modernização seletiva podemos notar claramente como Souza resgata o elo na corrente da seletividade da modernização, tendo o componente racial papel chave. Quando discorre sobre o processo de modernização ocorrido no Brasil, incitando o leitor a imaginar sobre o efeito de máquinas que poderiam

5 Para sermos precisos, o argumento de Souza diria que o aporte de uma economia emocional, fator não-econômico, embranqueceria, não apenas o dinheiro como sugere Lima. 
produzir melhor e mais eficazmente do que centenas de homens, numa sociedade movida por energia humana [negra] ${ }^{6}$, o autor enfatiza a desvalorização de toda a sociedade escravocrata, nas suas posições polares de senhor e escravo, bem como as relações personalistas baseadas nela. Esta perda, de autoridade do senhor e de perda de lugar do escravo no sistema produtivo, transformaria este no pária urbano, no habitante dos mocambos e futuras favelas.

No livro A construção social da subcidadania (Souza, 2012), tem-se a passagem de um argumento da centralidade da exclusão dos negros para a centralidade da classe social. $\mathrm{O}$ autor faz uma análise de obras clássicas da interpretação da formação social brasileira, tais como Gilberto Freyre, Luiz Werneck Vianna, Florestan Fernandes e Maria Sylvia de Carvalho Franco. A obra Homens livres na ordem escravocrata tem importância crucial, pois é por meio de sua releitura que Souza estabelece um vínculo entre escravos e dependentes livres para melhor pensar o seu conceito de ralé, que já vinha sendo construído em diálogo com Florestan Fernandes. O interessante na obra de Maria Sylvia (1974), é demonstrar a existência de homens desvinculados não apenas do processo produtivo, mas de todos os processos essenciais da sociedade. Isso reforça a ideia de Souza de que as práticas modernizantes antecedem a própria ideia de modernidade.

Souza faz um movimento de filiação à sociologia crítica aos termos de Pierre Bourdieu, que baseia o empreendimento de emancipação principalmente sobre a prática sociológica. Este ponto nos estimula a dialogar com a teoria de Souza por meio das críticas que Luc Boltanski adereça à Pierre Bourdieu. Para Souza haveria a necessidade de descortinar uma realidade em que os sujeitos são excluídos por questões de carências, faltas de incorporação de elementos necessários à luta cotidiana. Advoga, assim, pela assimetria entre o senso comum levado a cabo pelo discurso dos atores sobre si mesmos e o sociólogo, capaz de revelar àqueles a verdade sobre sua condição social. "Nesta posição, a sociologia é, portanto, tanto o instrumento para descrever a dominação como instrumento para a emancipação da dominação" (Boltanski, 2011 [2009]: 19). Segundo Luc Boltanski:

[...] a intensificação da diferença entre a ciência sociológica e conhecimento comum leva a uma subestimação dos efeitos da circulação de discursos sociológicos na sociedade e sua re-apropriação/re-interpretação pelos atores

6 A negridão dessa fonte de energia é convocada por Souza em nota de rodapé, onde lembra o leitor que os aristocratas eram carregados e substituíam a tração animal por tração humana. 
- o que é bastante problemático no caso de uma sociologia que reivindica a reflexividade (Ibid.: 21).

Percebemos que o principal ponto a ser interpelado, nesse caso, é o da conjugação deste uso duplo da sociologia: como instrumento de descrição e como arma de crítica, conjugação que Boltanski percebe como caudatária de um idealismo filosófico comum nos autores franceses críticos das décadas de 1960 e 1970 e ainda preponderante na academia nos dias de hoje. A sociologia como descrição da realidade não abandonaria uma postura crítica, na medida em que estariam incorporadas na própria descrição "recursos retóricos capazes de gerar indignação nos leitores" (Ibid.: 22) e, por consequência, alavancar a transformação social. Trata-se de colocar em curso uma sociologia capaz de resgatar o potencial da crítica por meio da descrição da vasta superfície em que os atores fazem da ação uma prática corporal, precisamente elemento que Souza busca na filosofia de Charles Taylor (1993) na combinação que este realça entre Wittgenstein e Bourdieu. Aqui, para além do subterrâneo oculto das estruturas, a sociologia descritiva vai no encontro de uma vasta dimensão do universo social, sem que causas ocultas sejam buscadas como razão explicativa universal e total ao submeter as análises aos imperativos do "imperialismo sociológico" (Boltanski, 2011; Rodrigues; Neves; Anjos, 2016). Ao mesmo tempo, isso levaria Souza a não desconsiderar a vasta produção acadêmica que traz evidências inquestionáveis de discriminação racial. Ainda, o levaria a reler Florestan, percebendo as discrepâncias existentes entre os depoimentos contidos no livro $A$ Integração do Negro na sociedade de classes e a sua análise.

\section{Interseccionalidade como proposta teórico-metodológica}

Na primeira parte desse artigo, procurou-se expor o pensamento de Jesse Souza, demonstrando o percurso teórico que esse autor segue para defender a primazia das questões de classe na análise da desigualdade brasileira. Na busca por traçar um caminho alternativo que amplie as possibilidades de compreensão sobre os processos de exclusão sem que necessariamente adotemos uma hierarquia do que mais importaria, seja classe, gênero ou raça, buscamos uma perspectiva já bastante difundida no campo de estudos feministas e nos estudos raciais, trazida pela ideia da intersecção. A metáfora da intersecção (em alusão ao cruzamento de estradas) localiza as pessoas num lugar associado a sistemas múltiplos de subordinação, sendo fundamental em qualquer análise "buscar capturar as consequências estruturais e dinâmicas da interação entre dois ou mais eixos" (Crenshaw, 2002: 177). Estes eixos não agiriam separadamente, 
fazendo necessário tomar uma perspectiva na qual uma multiplicidade de fatores gera situações de exclusão.

Como um conceito deriva das críticas levantadas por ativistas dos movimentos sociais no escopo das lutas políticas identitárias, em especial de intelectuais negras nos Estados Unidos e na Grã-Bretanha nas décadas de 1960 e 1970 que destacavam o discurso político excessivamente homogêneo no qual generaliza-se, em especial a questão das mulheres, diante da branquitude (Davis, 2013). Neste contexto, Kimberlé Crenshaw coloca o termo interseccionalidade em uso mais abrangente e em escala internacional, enfatizando estruturas interseccionais da desigualdade ao adicionar, multiplicar e reforçar hierarquias particulares em locais específicos (Ferree, 2009).

No artigo Demarginalizing the intersection of race and sex, Crenshaw (1989) realça a ideia de interseccionalidade por meio de uma análise de diversos processos judiciais nos quais os sistemas de opressão são tornados invisíveis. Levando em consideração alguns casos empíricos, nos quais a autora percebe diferentes formas de discriminação que se articulam na opressão específica às experiências das mulheres negras nos Estados Unidos, ela depreende que os tribunais e as cortes de justiça mostram-se incapazes de lidar com a interseccionalidade. Quando as demandantes dos processos são mulheres negras, as decisões, no máximo, admitem elementos de gênero, promovendo a ideia de que a experiência vivida entre mulheres brancas e negras seriam equivalentes (ou que a opressão seria condicionada ao fato de serem mulheres). Essa falta de atenção aos múltiplos terrenos nas quais as identidades são construídas seria fonte de uma marginalização dupla, nas quais as mulheres negras seriam marginalizadas tanto em sua identidade de gênero como de raça (Crenshaw, 1991: 1244).

Crenshaw (2002) chama atenção para o fato de que a invisibilidade do caráter interseccional da dominação e da opressão torna necessário repensar a importância da diferença intragrupo. Assim, quando certos problemas são categorizados como manifestações da subordinação de gênero de mulheres ou da subordinação racial de determinados grupos, surge um duplo problema de superinclusão e de subinclusão. $O$ primeiro diz respeito a uma condição imposta de forma específica ou desproporcional a um subgrupo de mulheres, sendo simplesmente definido como um problema de mulheres. Os aspectos que tornam um problema interseccional são absorvidos pela estrutura de gênero. Já a subinclusão surge quando um subconjunto de mulheres subordinadas enfrenta um problema, em parte por serem mulheres, mas isso não é produzido como um problema de gênero, porque não faz parte da experiência das mulheres dos grupos dominantes. Outra situação de subinclusão ocorre quando existem 
distinções de gênero entre homens e mulheres do mesmo grupo étnico ou racial. Se uma condição ou problema é específico das mulheres do grupo étnico ou racial e, por sua natureza, é improvável que venha atingir aos homens, sua identificação como problema de subordinação racial ou étnica fica comprometida. A dimensão de gênero do problema o torna invisível enquanto uma questão de raça ou etnia. A ideia de Crenshaw é que diversos fatores relacionados às identidades sociais de todas as mulheres, ainda que sujeitas ao peso da discriminação de gênero, são diferenças que fazem diferença na forma com que grupos vivenciem a discriminação. Estes fatores tais como classe, casta, raça, cor, etnia, religião, origem nacional e orientação sexual não poderiam ser descartados de antemão como elementos distintivos de um processo de exclusão, na medida em que sua articulação pode gerar diferentes resultados.

Como salienta Patrícia Hill Collins (2000), o paradigma interseccional nos faz recordar que a opressão não pode ser reduzida a um tipo fundamental e que há uma combinação de fatores que se articulam na produção da injustiça. É precisamente essa ideia que se pretende enfatizar ao criticar as abordagens que criam hierarquias entre distintas formas de desigualdade. Collins traz a ideia de uma matriz de dominação, que se refere ao modo que este cruzamento de opressão é organizado. Uma matriz de dominação poderia ser vista como uma organização histórica específica de poder nos quais os grupos sociais estão imersos e sob as quais os relacionamentos individuais se amparam. As matrizes de dominação que influenciam nas trajetórias individuais, ao contrário da ideia de sobreposição, somatório ou encontro advindo do conceito de interseccionalidade, busca inserir a percepção do intercâmbio de processos de dominação que ora podem ter seu fundamento em elementos de gênero, raça e classe. Poderíamos pensar como exemplo o trabalho doméstico no Brasil. Sabe- se que essa atividade, desvalorizada socialmente e localizada na base da estrutura ocupacional, é majoritariamente uma área de atuação de mulheres pobres (Lima; Prates, 2019). Isso nos levaria a pensar em gênero e classe como fatores explicativos para as desigualdades no serviço doméstico. No entanto, esses mesmos autores revelam que as mulheres negras estão sobre representadas nesse tipo de trabalho, demonstrando assim a importância do fator racial, que nesse caso específico, parece se sobrepor a questões de gênero e classe. Ou seja, o trabalho doméstico não é simplesmente um trabalho de mulheres ou de pessoas pobres, mas sim de mulheres, negras e pobres.

Collins fundamenta seu argumento na ideia de que as matrizes de dominação seriam organizadas por meio de quatro domínios de poder inter-relacionados: estrutural, disciplinar, hegemônico e interpessoal. Cada domínio serviria 
a um propósito particular: o estrutural organizaria a opressão enquanto o disciplinar a administraria; o domínio hegemônico justificaria a opressão e o interpessoal influenciaria experiências cotidianas e a consciência individual que delas sucedem. Diante deste ponto, mecanismos de opressão são tomados em termos organizacionais e procedurais, bem como na relação de justificação e legitimação no nível das interações pessoais.

Se diante desta breve retomada podemos perceber as amplas possibilidades metodológicas e conceituais que o emprego da interseccionalidade implica na pesquisa sociológica, também se faz fundamental levantar alguns pontos nos quais operar via intersecções se faz problemático. Ainda que se faça necessário compreender os sujeitos como entrecortados por diversas camadas que compõem o plano político das lutas em que se inserem, fica evidente que essa não é tarefa fácil. Como empreendimento metodológico, pensar em intersecções pode ser desafiador na medida em que os atores podem experienciar diferentes dimensões dos mecanismos de opressão que se alteram no tempo e no espaço. O que hoje pode parecer fundamental numa luta política pode ser algo de menor importância em outro momento. Estas transformações, ainda que reconheçamos fortes tendências de inércia no campo da mudança social, não devem ser descartadas prontamente.

Myra Marx Ferree (2009) sugere um modelo de interseccionalidade interativa para dar conta destas mudanças, no qual a sobreposição de identidades sociais é melhor compreendida não como uma coleção de "pontos de intersecção", mas como uma figuração nos termos de Norbert Elias ou um campo nos termos de Pierre Bourdieu. A ideia principal é tomar a intersecção como um processo e não como uma localização específica ocupada por grupos e indivíduos. Mais uma vez retoma-se a ideia defendida nesse artigo de que seria uma questão empírica ver quais conceitos são importantes às configurações da desigualdade no contexto em questão, já que alguns aspectos da ordem social, apesar de aparente estabilidade, podem apresentar transformações significativas. Essa seria uma contribuição fundamentada nos desenvolvimentos teóricos do construtivismo em detrimento do estruturalismo. Ferree sugere a interseccionalidade como redes de sentidos e defende a análise por meio dos quadros de interação - ou análises de enquadramento como em Erving Goffman (1986).

A sugestão de Ferree não difere muito daquela apresentada pelos proponentes do relacionalismo (Correa, 2014). Neste sentido, a melhor metáfora para a intersecção de modos de opressão não seria o de um cruzamento de estradas, mas de uma rede ou de um campo de relações nas quais as lutas por oportunidades, poder e privilégio tomam lugar (Desmond; Emirbayer, 2009; Emirbayer, 
1997). Na perspectiva dos autores, uma análise interseccional que rompe com os modos antiquados de pensamento (como a sociedade sendo uma "matriz de dominação" como sugere Collins) e adota uma perspectiva totalmente relacional nos múltiplos modos de opressão (como a interseccionalidade interativa de Ferree), não é uma opção, mas um pré-requisito para compreender plenamente a natureza da identidade racial e da dominação racial.

Embora adotemos esta ideia da interseccionalidade como pré-requisito, nos parece mais frutífero pensar nos seus desdobramentos como ferramenta metodológico-conceitual que auxilia na compreensão de fenômenos da desigualdade que, aparentemente, seriam dominados por "categoriais principais", dado que as relações raciais (assim como de classe, gênero, orientação sexual, identidade nacional e outras formas de pertencimento) não operam dentro de um vácuo isolado de outros modos de dominação.

Para Leslie McCall (2005) há pouca discussão metodológica sobre, afinal, como seria possível abordar no plano empírico a representação de um fenômeno múltiplo e complexo. Além disso, a autora sugere que muito pouca atenção é dedicada à classe social na nova literatura da interseccionalidade que vem priorizando raça e gênero no exame das desigualdades estruturais. Os autores que utilizam a ideia de interseç̧ão apresentariam três abordagens principais até o momento: abordagens das complexidades anti, intra e inter categóricas.

A primeira delas, que a autora sugere ser a mais bem-sucedida até agora em satisfazer as demandas por complexidade, é baseada numa metodologia da desconstrução e rejeição da utilização de categorias analíticas. Nessa abordagem, a vida social é considerada demasiadamente complexa e repleta de múltiplas e fluidas determinações de sujeitos e estruturas para que sejam fixadas. As categorias fixas seriam nada mais que "ficções sociais simplificadoras que produzem desigualdades no processo de produção da diferença” (p. 1773).

A abordagem intra-categórica é aquela que inaugura os estudos da interseccionalidade. Assim, como a primeira abordagem, interroga o processo de criação e definição de fronteiras e reconhece as relações estáveis e até mesmo duráveis que as categorias sociais representam em um dado período e lugar, embora também mantenha uma postura crítica em relação a categorias. A abordagem é assim denominada "porque autores trabalhando nessa vertente tendem a focar grupos sociais particulares em pontos de intersecção negligenciados... com intuito de revelar a complexidade da experiência vivida dentro de tais grupos" (p. 1774)

A terceira abordagem, intercategórica, seria a menos utilizada e conhecida por pesquisadores e é introduzida pela autora com base no exemplo de sua 
pesquisa empírica. Ela sugere que nessa perspectiva os pesquisadores adotem provisoriamente "categorias analíticas existentes para documentar relações de desigualdade entre grupos sociais e mudanças de configurações da desigualdade ao longo de dimensões múltiplas e conflitantes" (p. 1773). Por meio de um estudo caráter quantitativo, McCall compara duas cidades norte-americanas com grandes tradições sindicais de trabalhadores de colarinho azul (setor industrial). Detroit com sua recente história de desindustrialização, exibe, por um lado, baixa desigualdade salarial racial entre homens, mas elevada desigualdade salarial e de classe entre mulheres empregadas. Em contraste, uma cidade pós-industrial como Dallas apresenta uma estrutura oposta de desigualdade - é mais marcada por desigualdade de raça e classe do que gênero.

Em estudos de caráter quantitativo parece ser mais evidente a possibilidade de comparar entre diferentes casos os fatores mais significativos no que se refere ao desencadeamento de estruturas de opressão que resultam em exclusão e desigualdades sociais. Em contrapartida, nos estudos qualitativos tal comparação se depara com intrincadas situações, em que dificilmente o pesquisador consegue separar elementos que se dão no nível da experiência e no plano do sensível de maneira sobreposta e concomitante. Ao invés de buscar tal separação, concluímos que a análise sociológica sobre processos de exclusão deve ser complexificada e desierarquizada, indo ao encontro das críticas filosóficas da modernidade, articuladas pelo questionamento da sustentação da sociedade moderna bem como seus filosofias fundantes, disciplinas e conceitos.

\section{Considerações finais}

Exploramos nesse artigo questões que convergem no estudo das desigualdades sociais e que nos conduzem às possibilidades de experimentação teórico-metodológica, bem como nos convidam a uma reflexão da relação entre ciência e seus projetos políticos subjacentes. Em proposição de um diálogo com as correntes teóricas desenvolvidas na teoria sociológica e social contemporâneas, partimos da leitura da teoria das desigualdades desenvolvida nos estudos de Jessé Souza, em especial a atenção dedicada pelo autor na proposta de hierarquizar as questões mais importantes em relação as causas das desigualdades. Sem a pretensão de esgotar a discussão, procurarmos resgatar seus argumentos e trouxemos uma hipótese de guinada epistemológica em sua obra que vai da percepção de impossibilidade de sobredeterminação de categorias ao realce de classe como elemento constitutivo mais importante, atrelado ao projeto político de uma sociologia crítica. 
A perspectiva da interseccionalidade é retomada como um pré-requisito para reflexões sobre as formas de dominação e opressão. A ideia de intersecção emerge de uma série de textos de acadêmicos e de ativismos políticos que enfatizam a necessidade de pensarmos a vida dos sujeitos como composta por diversas camadas, nas quais se busca entrelaçar complexidades do plano da experiência com os desdobramentos políticos atrelados a um tipo de engajamento científico e político. A discriminação e as redes pelas quais se perpetuam são destacadas como diferenças marcantes nas vidas daqueles associados aos grupos em posição de vulnerabilidade.

Nosso objetivo neste artigo foi sublinhar a complexidade da temática que carrega e consequentemente seus desdobramentos teóricos, metodológicos e epistemológicos. Depreendemos das reflexões trazidas aqui que tanto a construção teórica quanto as análises empíricas enfrentam impasses quando partem de proposições que se pretendem gerais. Isso não exclui a associação que podemos suscitar de nossos materiais de pesquisa por meio de sujeitos e situações sociais que transbordam as realidades individuais, estimulando debates que transcendem $o$ particular e tornando possível o diálogo. Além disso, a multiplicidade de fatores que influenciam os mecanismos que produzem a exclusão nos convidam a abraçar a complexidade do social sem que necessariamente o façamos por meio de procedimentos que retirem o protagonismo dos atores como desencadeadores da transformação social no plano da experiência e no curso da história.

\section{Referências}

BOLTANSKI, Luc. On critique: a sociology of emancipation. Cambridge, UK, Polity, 2011. BOURDIEU, Pierre. A Distinção: crítica social do julgamento. Porto Alegre, Zouk, 2007. CORRÊA, Diogo Silva. Do problema do social ao social como problema: elementos para uma leitura da sociologia pragmática francesa. Revista Política \& Trabalho, v. 1, n. 40, pp. 35-62, 2014.

CRENSHAW, Kimberlé. Demarginalizing the intersection of race and sex: A black feminist critique of antidiscrimination doctrine, feminist theory and antiracist politics. University of Chicago Legal Forum, 1989.

. Documento para o encontro de especialistas em aspectos da discriminação racial relativos ao gênero. Estudos feministas, v. 10, n. 1, 2002, pp. 171-188.

HTTPS://DOI.ORG/10.1590/So104-026X2002000100011

Mapping the Margins: Intersectionality, Identity Politics, and Violence against

Women of Color. Stanford Law Review, v. 43, n. 6, 1991, pp. 1241-1299. 
DAVIS, Angela. Mulher, raça e classe. [S.l.]: Plataforma Gueto, 2013.

DESMOND, Matthew; EMIRBAYER, Mustafa. What is racial domination? Du Bois Review: Social Science Research on Race, v. 6, n. 2, 2009, pp. 335-355.

HTTPS://DOI.ORG/10.1017/S1742058X09990166

EMIRBAYER, Mustafa. Manifesto for a Relational Sociology. American Journal of Sociology, v. 103, n. 2, 1997, pp. 281-317.

HTTPS://DOI.ORG/10.1086/231209

FERNANDES, Florestan. A integração do negro na sociedade de classes. v. 1 - O legado da raça branca. São Paulo, Ática, 1978.

. O negro no mundo dos brancos. São Paulo, Difusão Europeia, 1972.

FERREE, Myra Marx. Inequality, intersectionality and the politics of discourse: framing feminist alliances. In: LOMBARDO, $\bigotimes$ Emanuela; MEIER, $\bigotimes$ Petra; VERLOO, Mieke (Org.). The discursive politics of gender equality: stretching, bending, and policy-making. New York, Routledge, 2009, pp. 86-104.

FRANCO, Maria Sylvia. Homens livres na ordem escravocrata. São Paulo, Ática, 1974.

GOFFMAN, Erving. Frame analysis: an essay on the organization of experience. Boston, Northeastern University Press, 1986.

HASENBALG, Carlos Alfredo. Discriminação e desigualdades raciais no Brasil. Belo Horizonte, Editora UFMG, 2005.

HASENBALG, Carlos Alfredo; SILVA, Nelson do Valle (Org.). Estrutura social, mobilidade e raça. São Paulo, Vértice, 1988.

HILL COLLINS, Patricia. Black feminist thought: knowledge, consciousness, and the politics of empowerment. Rev. 1oth anniversary ed. New York, Routledge, 2000.

HOUNTONDJI, Paulin. Conhecimento de África, conhecimento de Africanos: duas perspectivas sobre os Estudos Africanos. Revista Crítica de Ciências Sociais, v. 80, 2008, pp. 149-160.

LIMA, Márcia. Raça e pobreza em contextos metropolitanos. Tempo Social, v. 24, n. 2, 2012, pp. 233-254.

HTTPS://DOI.ORG/10.1590/So103-20702012000200012,

LIMA, Márcia; PRATES, Ian. Emprego doméstico e mudança social. Reprodução e heterogeneidade na base da estrutura ocupacional brasileira. Tempo Social, v. 31, n. 2, 2019, pp. 149-172.

HTTP://DX.DOI.ORG/10.11606/0103-2070.TS.2019.149291

MCCALL, Leslie. The Complexity of Intersectionality. Signs: Journal of Women in Culture and Society, v. 30, n. 3, 2005, pp. 1771-1800.

HTTPS://DOI.ORG/10.1086/426800

MIZRAHI, Mylene. Cabelos ambíguos beleza, poder de compra e "raça" no Brasil urbano. Revista Brasileira de Ciências Sociais, v. 30, n. 89, 2015, pp. 31-45. 
HTTPS://DOI.ORG/10.17666/308931-45/2015

QUIJANO, Aníbal. Colonialidade do poder: eurocentrismo e América Latina. In: LANDER, Edgardo (Org.). A colonialidade do saber: eurocentrismo e ciências sociais perspectivas latinoamericanas. São Paulo, CLACSO, 2000, pp. 227-278.

RODRIGUES, Léo Peixoto; NEVES, Fabrício; ANJOS, José Carlos dos. De coadjuvante a protagonista? A reflexão epistemológica das Ciências Sociais para Século XXI. Sociologias, v. 18, n. 41, 2016, pp. 14-23.

HTTPS://DOI.ORG/10.1590/15174522-018004101

SOUZA, Jessé. A visibilidade de raça e a invisibilidade de classe: contra as evidências do conhecimento imediato. In: (Org.). Invisibilidade da desigualdade brasileira. Belo Horizonte, Editora UFMG, 2006, pp. 71-95.

. A construção social da subcidadania: para uma sociologia política da modernidade periférica. $2^{\mathrm{a}}$ ed. Belo Horizonte, Editora UFMG, 2012.

. A modernização seletiva: uma reinterpretação do dilema brasileiro. Brasília, Editora UnB, 2000.

. A ralé brasileira: quem é e como vive. Belo Horizonte, Editora UFMG, 2009.

. Raça ou classe? Sobre a desigualdade brasileira. Lua Nova, n. 65, 2005, pp. 43-69.

TAYLOR, Charles. To follow a rule. In: CALHOUN, Craig (Org.). Bourdieu: critical perspectives. Chicago, University of Chicago Press, 1993.

WEBER, Max. A ética protestante e o espírito do capitalismo. São Paulo, Companhia das Letras, 2004.

Recebido em: 04/09/2018

Aprovado em: 20/03/2020

\section{Como citar este artigo:}

HERTZOG, Lucas e MELLO, Luciana Garcia de. Por uma abordagem interseccional das desigualdades: rupturas com visões hierarquizadas. Contemporânea - Revista de Sociologia da UFSCar, v. 10, n. 1, jan.- abril 2020, pp. 229-247. 
